\title{
Past, Present and Future of Iranian Naval Health and Maritime Medicine
}

\author{
Ali Reza Khoshdel ${ }^{1, *}$ \\ ${ }^{1}$ Epidemiology Research Centre, AJA University of Medical Sciences, Tehran, IR Iran \\ "Corresponding author: Ali Reza Khoshdel, Epidemiology Research Centre, AJA University of Medical Sciences, Tehran, IR Iran. Tel/Fax: +98-2188337909, E-mail: \\ a.khoshdel@ajaums.ac.iralikhoshdel@yahoo.com
}

Received 2016 February 13; Accepted 2016 February 13.

Keywords: Naval Medicine, Military Medicine, Maritime Medicine

The history of the Persian (Iranian) fleet backs to more than 3000 years ago. Navy was the most organized force in the ancient Persia. Xerxes (Khashayarsha, the fourth king of the Achaemenid Empire ruled from 486 B.C.) arranged the most famous fleet in the Persian military forces (Figure 1). According to Herodotus, the size of Xerxes' expeditionary force was over two million men and four thousand ships (1). The vast oceans and seas in Asia and Europe witnessed bravery and proficiency of the Persian military forces in carrying out their missions for keeping security and spreading the parade of civilization (Figure 2). Therefore, it is quite expected that the health of the troops was among the main priorities for the ancient Persian army in order to maintain their power and continue their victories.

Persia was on the cross road of several cultures. Then, Persian naval force played as an inductor for reciprocal cultural exchange between India and China from one side and Greek and Rome from the other side. They also played a prominent role for merging the ancient medical science from these cultures. Consequently, the medicine was enriched in Persia with the spiritual believes of Iranian people. Of prominent importance, Iranian medicine mainly focused on a "healthy life style" in every aspects of life and took spirituality and psychological dimensions of health into account in all medical interventions (2). Therefore, Simurgh and Golnar (pomegranate flowers) were considered as symbols of spiritual health which were granted from the king to soldiers as their guardians (3) (Figure 3).

The danger of seas is still the same as it was and marine operations are still full of natural challenges. Nevertheless, after thousands of years, the appearance, performance, missions and nature of the modern naval forces have substantially changed by new technologies. Iranian Naval Force has dramatically evolved during the past recent decades in terms of modern indigenous made fleets, missiles, communication tools, radars, submarines and flying systems. In parallel, the medical needs and require- ments of naval forces have markedly evolved in all health dimensions. In addition, the epidemiology of diseases passed three transitional periods during the last centuries that presented emerging challenges for naval forces. Accordingly, marine and submarine medicine faces several sophisticated conditions now. Obviously, the standard health including physical, mental, social and spiritual for military forces is higher than the general population to enable them for special operations in nonconventional conditions, particularly when they battle an enemy. Therefore, naval forces not only should be physically fit, but also must be mentally and spiritually prepared. Furthermore, their families must be properly supported and socially protected to ensure troops for being fully committed in their missions.

In all of these fields, prevention has a priority to treatment and is more cost-effective. Primordial prevention includes defining and controlling the health risk factors, which depends on an integrated research program as well as a functional information technology and data management. To confront emerging and re-emerging epidemics, data gathering, recording, analyzing, and management, including important information about disease frequency and distribution, particularly by geographic information system and remote sensing, is a major task for military services. Then, establishing and improvement in the surveillance by modern technologies including geographic information system (GIS) and remote sensing are important priorities for marine medicine, which could be facilitated by satellite services and modern drones. In addition, health education must be considered as a critical step toward disease prevention as well as patients care, where virtual systems might play a major role.

Beside individual hygiene, it is easier to control environmental factors for diseases by modern tools. Furthermore, healthy nutrition in naval forces could be planned and achieved to be a model for the civilian population. 


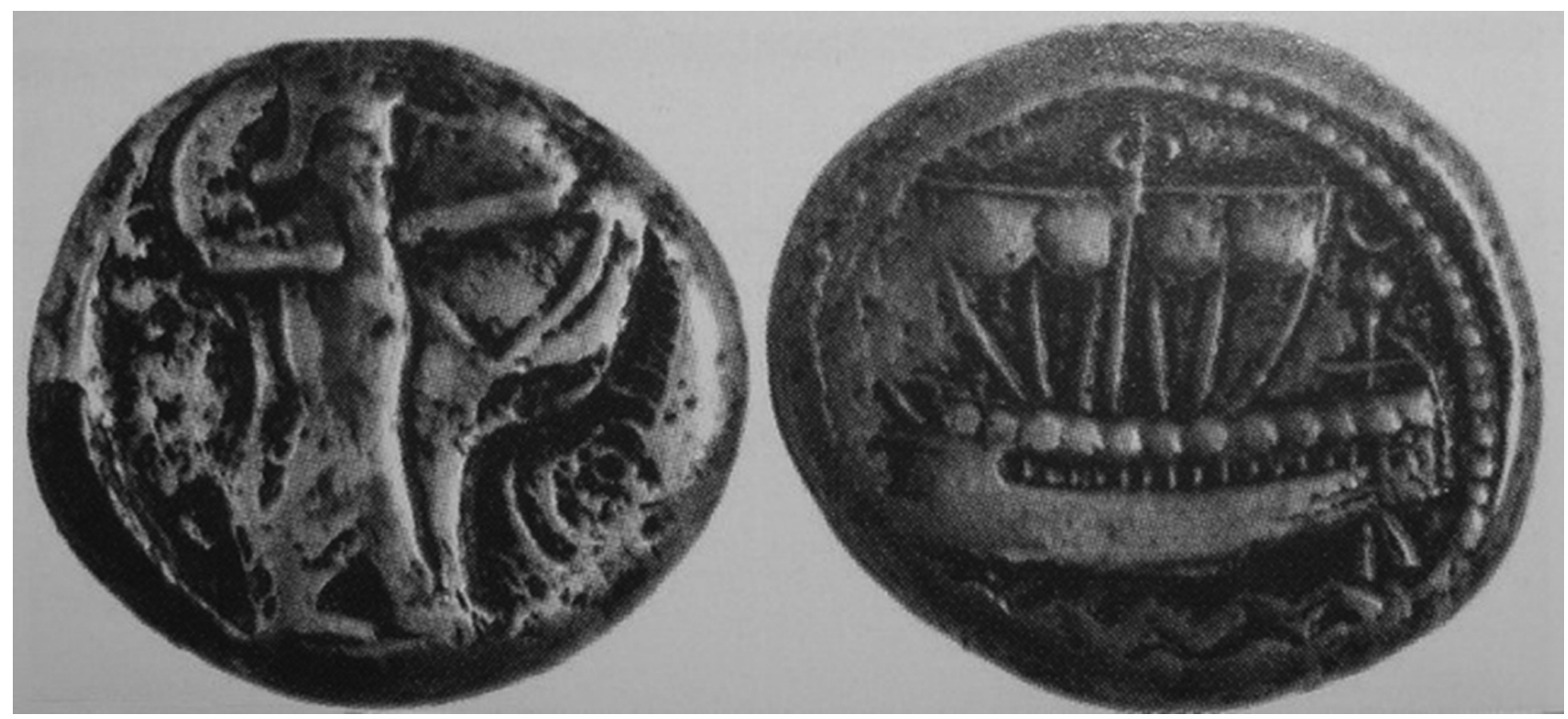

On one side it shows Artaxerxes II (404 - 358 B.C.) standing to the right holding a bow and on the other side there is a ship; of course, the book says that is probably a Phoenician ship and the coin was struck by Straton I, satrap of Sidon. Anyway, it shows a war ship which was used in the ancient Persian empire, it has four sails and seems to be a large ship.

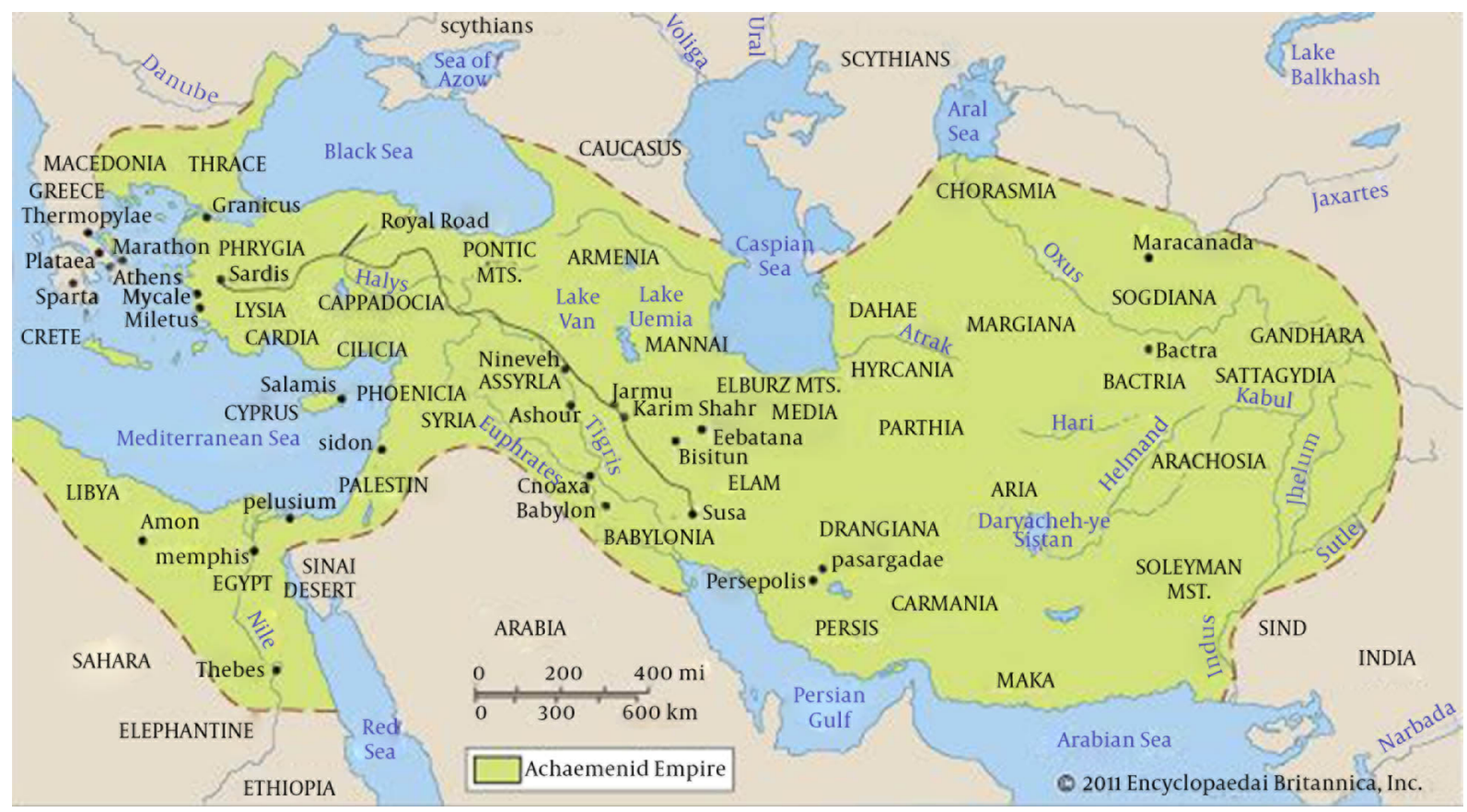

Figure 2. Achaemenid empire territory (522 B - $486 \mathrm{BC}$ ), the cross road between the the ancient civilizations and surrounded by six seas. The Empire arranged one of the largest organization for military fleets.

Naval force could also become a smoke-free population and thereby considerably control the burden of diseases.
Of paramount importance, oral health must be on the target for naval forces. Prevention of oral diseases and im- 

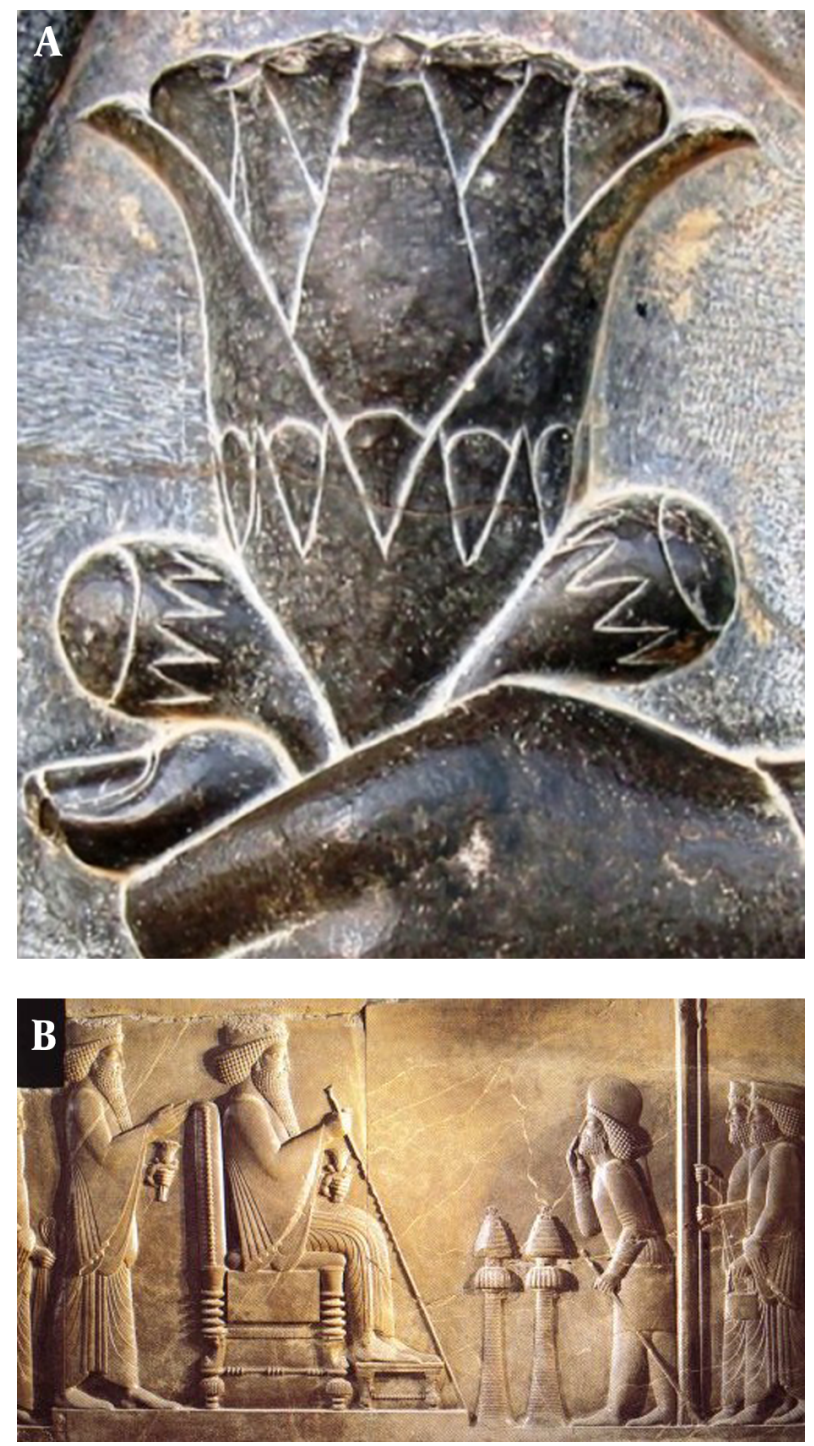

Figure 3. Punica granatum or pomegranate flower was considered as a holy magic medicine (PANEL A) and symbolized spiritual health in the traditional Persian medicine, that made soldiers resistance (Rooyeen-tan) against their enemies (PANEL B).

proving dental health is inexpensive but very effective. Similarly, mental health must be considered as among major priorities for naval and submarine forces due to their frequent separation from their families and longtime and extraordinary missions. Despite limitations, physical activity of naval force should also be facilitated. This holistic plan would lead to the ultimate goal of "healthy combatant" in maritime medicine.

Iran has the 8th largest military force in world ranking (4) (Figure 4). Importantly, the totality of evidence indicates that Iranian maritime activity in support of the Ira- nian strategic objective of regional power and influence is evolving and expanding against potential offenders, smuggling, and illegal transport (5). Then, the troops must be aware of the potential of disease transmission during their exposure to environmental threats from other regions. Therefore, appropriate vaccination programs, chemical prophylaxis and quarantine must be considered according to the guidelines. Iran is the only country in the Persian gulf region with submarines in various classes (6). Therefore, unique medical support must be provided by Iranian military health system including submarine hygiene and hyperbaric medicine (5). For instance, modern toxicology must be applied to detect and manage non-conventional chemicals used in engines and electrical power units of submarines (Figure 5).

From the medical care side, modern technologies have been being served for Iranian naval force hospitals from laser technologies to minimal invasive surgeries, transplantation, reconstructive operations and intensive care services, as well as rehabilitation and imaging technologies. Iranian maritime medicine has successfully implemented telemedicine and is preparing for telerobotic surgery.

Apart from the above mentioned strategies, there are huge research opportunities in the naval medical system. There is a good access to the source of sea and undersea biologic environment which could be applied for health purposes, i.e. as a nutrient or as a medicine. On the health front, there has been increasing interest in marine microbes, particularly bacteria, with studies demonstrating that they are a rich source of potential drugs. It is estimated that annually nine billion USD biologic products are extracted from the bottom of seas and oceans, mainly with medical applications. For instance, anti-inflammatory products and tissues for bone transplant have been extracted from coral cliffs, anti-HIV materials have been produced from sponges, and antibacterial medicine has been attained from the crabs in the eastern oceans. Some marine biologic products have also been applied for tuberculosis, malaria, and skeletal diseases. In 2011, there were over 36 marine-derived drugs in clinical development, including 15 in the cancer field. Besides, marine biologists have promoted a grand plan for ocean prospecting in order to find biologic fuels that might overshadow the future of global energy resources (7).

Importantly, Iranian armed force has established the school of aerospace and submarine medicine, which is unique in the region. This gathers a precious team of academics, provides several opportunities for research and education in the field of naval health and submarine medicine and opens international collaborations in this field. 
Figure 4. The Size of Military Worldwide Demonstrating the 8th Place of Iran in the World Ranking

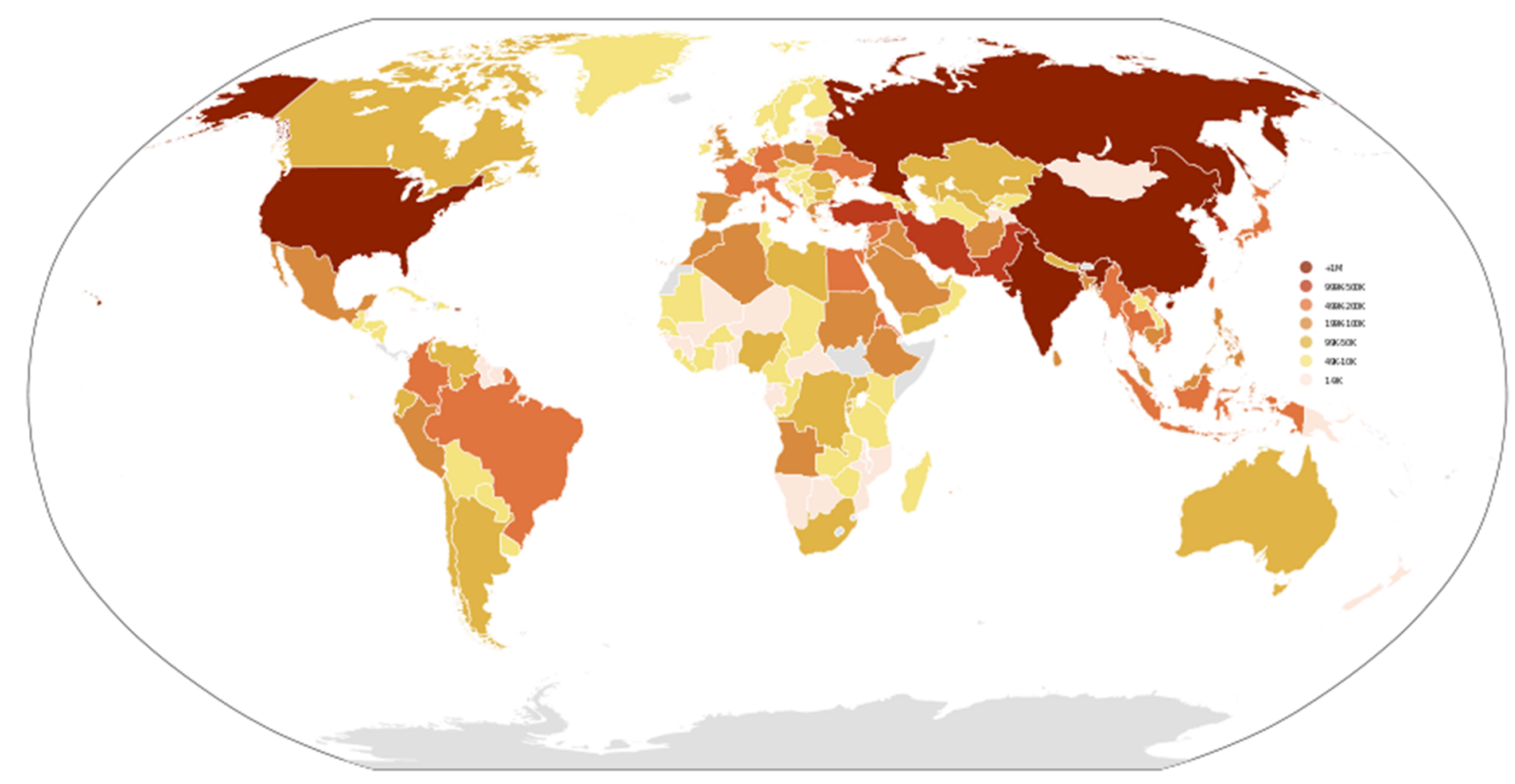

The following list is sourced from the 2014 edition of "The Military Balance" published annually by the International Institute for strategic studies.

Finally, because of international collaborations, naval or maritime hospitals are good places to promote modern surgical and medical treatments and could be good targets for medical tourism and provide the best medical service for military forces from friend nations. This would tighten our international military relationship with other nations for peace and health purposes.

In conclusion, Iranian naval health and maritime medicine has several opportunities for scientific improvement and being a role model in the national and global health system. 

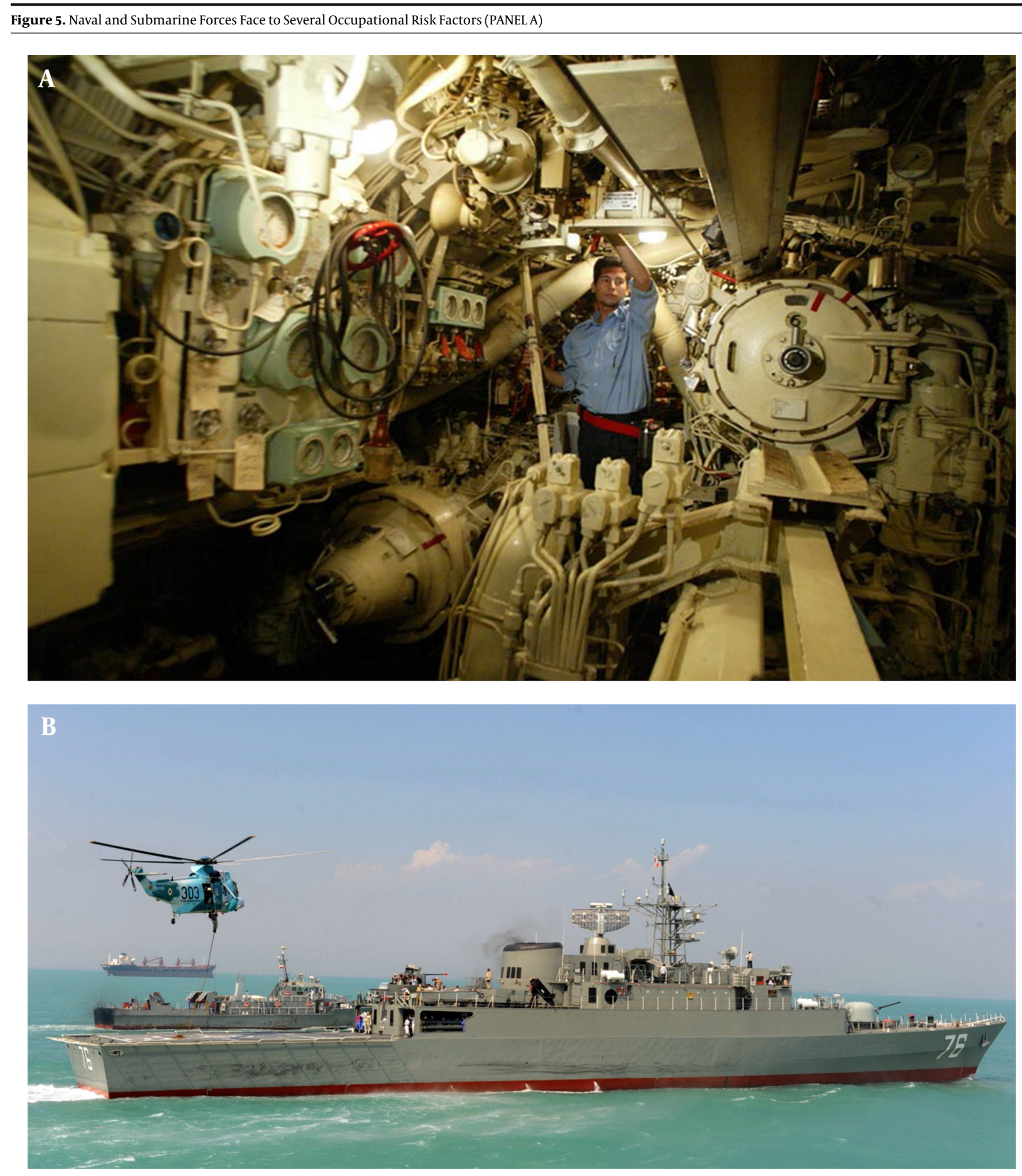

PANEL B: The bottom photo is the domestically made Jamaran destroyer, lunched in the Persian gulf in 2009. This illustration demonstrates an exercise for evacuation of an injured patient.

\section{References}

1. Stecchini LC. The Persian Wars. Metrum; 2016.
2. Pourahmad J. History of medical sciences in Iran. Iran J Pharm Res. 2008;7:93-9.

3. Khoshdel AR, Lashkari MH. From the Persian Ancient Dramas, Jamm 
and Simurgh Toward the Modern Military Medicine. J Arch Mil Med. 2013;1:1-5. doi: 10.5812/jamm.15082.

4. International institute for strategic studies . The Military Balance. London, UK: IISS; 2014.

5. Harmer C. Iranian Naval and Maritime Strategy. Washington, USA: Institute for the Study of War; 2013.

6. Nuclear Threat Initiative . Iran Submarine Capabilities Washington DC: NTI; 2015. [cited 21.8.2015]. Available from: http://www.nti.org/ analysis/articles/iran-submarine-capabilities/.

7. Directorate for science TAIOIFP. The future of the ocean economy exploring the prospects for emerging ocean industries to 2030. Organization for economic co-operation and development; 2012. 